\title{
Effect of La addition on microstructure and mechanical properties of hypoeutectic Al-7Si aluminum alloy
}

\author{
Xiao-yan Wu', Wei Luo', Hua-rui Zhang', Hu Zhang', *Hai-tao Jiang' \\ 1. National Engineering Research Center for Advanced Rolling Technology, University of Science and Technology Beijing, Beijing 10083, China \\ 2. School of Materials Science and Engineering, Beihang University, Beijing 100191, China
}

\begin{abstract}
The effect of La addition (0, 0.1, 0.2, 0.4, wt.\%) on the microstructure, tensile properties and fracture behavior of $\mathrm{Al}-7 \mathrm{Si}$ alloy was investigated systematically. It is found that the La appears in the Al-7Si alloy in the form of $\mathrm{Al}_{4} \mathrm{La}$ and $\mathrm{Al}_{2} \mathrm{Si}_{2} \mathrm{La}$ phases. La addition can refine the secondary dendrite arm spacing (SDAS) and eutectic Si particles, which are decreased by $7.9 \%$ and $7 \%$, respectively, with the optimal La content of 0.1 wt. $\%$. Because when $0.1 \mathrm{wt} . \% \mathrm{La}$ is added, a relatively higher nucleation undercooling of $37.47^{\circ} \mathrm{C}$ is observed. Higher undercooling degree suggests that nucleation is accelerated and subsequent growth is restrained. After T6 heat treatment, compared with the without $\mathrm{La}$, the ultimate tensile strength of the alloy with $0.1 \mathrm{wt} . \% \mathrm{La}$ is enhanced by $5.2 \%$ from $333 \mathrm{MPa}$ to $350.2 \mathrm{MPa}$ and the elongation increases by $73 \%$ from $7.37 \%$ to $12.75 \%$, correspondingly. The fracture mode evolves from the ductile-brittle mixed fracture to ductile fracture mode. However, when La element content reaches a certain value of $0.4 \mathrm{wt} . \%$, serious segregation takes place during the solidification process. The formed brittle phases deteriorate the tensile properties of the alloy and the fracture mode of Al7Si-0.2/0.4 La changes to mixed ductile-brittle fracture mode.
\end{abstract}

Key words: La addition; Al-7Si alloy; microstructure; mechanical property

CLC numbers: TG146.21

Document code: $\mathrm{A}$

Article ID: 1672-6421(2021)05-481-07

\section{Introduction}

Aluminum alloys have been widely used in automotive industry as structural parts with superior mechanical performances to meet the lightweight development of automobile. Al-7Si alloys are the representative of aluminum alloys with excellent microstructure and properties ${ }^{[1,2]}$ and are extensively used in wheels. It has been proved that the mechanical properties of cast Al-7Si alloy are determined by the microstructural characteristics, such as the morphology and size of $\alpha$-Al primary phase ${ }^{[3]}$, eutectic Si particles ${ }^{[4]}$, and some precipitates $\left(\mathrm{Mg}_{2} \mathrm{Si}\right.$ and Fe-rich phase) ${ }^{[5]}$ and so on. Many efficient methods have been proposed to modify the morphology and size of $\alpha$-Al primary phase and eutectic Si particles, including chemical modification ${ }^{[6]}$, quench modification ${ }^{[7]}$, thermal

\section{*Hai-tao Jiang}

Male, born in 1976, Ph.D, Professor. His research interests mainly focus on the processing and fabrication of metal materials. He has published above 200 papers in international and domestic journals so far

E-mail: jianght@ustb.edu.cn

Received: 2020-12-24; Accepted: 2021-06-15 modification ${ }^{[8]}$ and so on. Recently, the addition of rare metals as modifiers to these alloys has attracted considerable interest ${ }^{[9-11]}$.

Rare earth elements are known as "industrial vitamins", which can increase product variety and improve productivity. The atomic radius of rare earth element is $0.174-0.204 \mathrm{~nm}^{[12]}$, which is larger than the atomic radius of aluminum $(0.143 \mathrm{~nm})$. In the molten aluminum, rare earth elements are more active which is easy to accumulate at the crystal surface, resulting in a decrease in the surface tension at the interface between the new and the old phase ${ }^{[13]}$. A surface active film will be formed on the interface between the crystal grains and the molten metal to prevent the crystal grains from continuing to grow. The rare earth elements in the aluminum alloys play a role in refining and purifying the melt during melting process. At the same time as an alloying element, it can play a role of refinement and modification in aluminum alloys, resulting in grain refinement strengthening and solid solution strengthening and precipitation hardening ${ }^{[14,15]}$. Studies have shown ${ }^{[16,17]}$ that rare earth modified needle-like and coarse flake-like eutectic silicon into granular or rodlike shape. In addition, rare earth elements are slightly 
soluble in aluminum alloy and react with other elements to form high melting point compounds during the solidification process. The performance of the alloy is strengthened because these high melting point rare earth compounds exist in the form of a network or skeleton disperse in the dendrites. Its combination with the matrix is relatively firm, which can strengthen and stabilize the grain boundary. Among all the rare earth elements, the most widely investigated rare earth elements include $\mathrm{La}, \mathrm{Ce}$, Er, Sc, Eu and $\mathrm{Yb}$ in Al-Si alloys. Gammer et al. ${ }^{[18]}$ showed that among all the rare earth elements, Eu and La have the strongest ability to modify the microstructures as single addition element in aluminum alloy. So La was selected as the addition element in this study due to the low cost.

It has been known that adding La into aluminum alloy can effectively optimize the microstructures and mechanical properties ${ }^{[19,20]}$. Though many research works have been carried out to report the modification effect of La on eutectic Si particles, its comprehensive effects in controlling the microstructures and mechanical properties have not been elucidated clearly. What's more, there is a lack of sufficient information about the existence form of La element. It is also essential to investigate the optimal addition content of $\mathrm{La}$ in the Al-7Si alloy to obtain the desired result and guide the practical production. Therefore, in the present work, the influence of rare earth $\mathrm{La}$ on microstructures and mechanical properties of Al-7Si alloy was investigated and discussed in detail.

\section{Experimental procedure}

A series of Al-7Si- $x$ La alloys with different addition content of La element $(0,0.1,0.2,0.4$, wt.\%) were prepared using low pressure die casting technique. The raw materials were commercial Al-7Si alloy and Al-20\% La master alloy. During the low pressure die casting process, the raw materials were melted in an electric resistance furnace at a constant temperature of $800{ }^{\circ} \mathrm{C}$. The melt was magnetically stirred at this temperature for $30 \mathrm{~min}$ and then was poured into a permanent steel mold which was pre-heated to $200{ }^{\circ} \mathrm{C}$. The castings were cooled to room temperature in the air. The specimens were tested at ascast state and $\mathrm{T} 6$ heat-treated state. The T6 heat-treated samples were solution treated at $535^{\circ} \mathrm{C}$ for $4 \mathrm{~h}$, quenched in warm water of $50{ }^{\circ} \mathrm{C}$, aged at $170{ }^{\circ} \mathrm{C}$ for $8 \mathrm{~h}$ and finally cooled to room temperature in the air.

The rod-like tensile testing specimens (gage length of $25 \mathrm{~mm}$ and diameter of $6 \mathrm{~mm}$ ) were prepared using wire cutting and the tensile testing was carried out on an Instron 8801 testing machine with tensile speed of $1 \mathrm{~mm} \cdot \mathrm{min}^{-1}$ at room temperature. To ensure the reproducibility and accuracy, three specimens were tested and their average values were taken as the final mechanical properties. Specimens for microstructural analysis were extracted from the end of the corresponding tensile specimens. Specimens after grinding, mechanical polishing and then etched using a mixture of $\mathrm{HF}$ and $\mathrm{H}_{2} \mathrm{O}$ were observed by optical microscopy (OM), scanning electron microscopy (SEM) and electron probe micro analysis (EPMA) which equipped with wavelength dispersive spectroscopic (WDS). Field emission scanning electron microscopy (FM-SEM) coupled with energy dispersive spectrometry (EDS) was used to conduct the phase and surface fracture examination. X-ray diffraction (XRD) was conducted to characterize the phase constitution of Al-7Si$x$ La alloys $(x=0,0.1,0.2,0.4$, wt.\%). The differential scanning calorimeter (DSC) instrument under Ar atmosphere was used to measure the undercooling degree with constant heating rate of $10^{\circ} \mathrm{C} \cdot \mathrm{min}^{-1}$ from $500{ }^{\circ} \mathrm{C}$ to $700^{\circ} \mathrm{C}$. The Image-Pro Plus (IPP 6.0) software was used to measure the size of eutectic Si particles and secondary dendrite arm spacing (SDAS).

\section{Results and discussion}

\subsection{Thermal analysis}

Figure 1 shows the solidification DSC curve of the heat flow difference of A1-7Si- $x$ La alloy between the reference and the sample cells versus the temperature at a constant rate of $10^{\circ} \mathrm{C} \cdot \mathrm{min}^{-1}$. The solidification process is exothermic which is clearly present in Fig. 1. During the solidification process, two distinct solidification exothermic peaks are observed for Al7Si alloy [Fig. 1(a)] and three exothermic peaks are observed for Al-7Si-0.1La alloy [Fig. 1(b)]. The first peak (A) observed corresponds to the solidification of the primary Al phase and then, the following second peak (B) corresponds to the eutectic reaction. The third exothermic peak (C) corresponds to the formation of intermetallics, especially the La-rich phase in the Al-7Si- $x$ La alloy ${ }^{[17]}$. The onset temperature of the first exothermic inflection points is regarded as the nucleation temperature of grains $\left(T_{\mathrm{N}}\right)$. The second exothermic inflection point of the alloys is deemed as the eutectic nucleation temperature $\left(T_{\mathrm{E}}\right)$. The values of $T_{\mathrm{N}}$ and $T_{\mathrm{E}}$ obtained from the DSC curves are summarized in Table 1 . It can be obtained that the addition of La causes the increase of $T_{\mathrm{E}}$ and $T_{\mathrm{N}}$.

Undercooling degree is an important parameter determining the nucleation rate. The nucleation undercooling degree could be obtained according to Ref. [21] and the equations are as follows:

$$
\begin{aligned}
& T_{\mathrm{E}, \mathrm{Literature}}-T_{\mathrm{E}, \text { Measrued }}=\Delta \varepsilon \\
& T_{\mathrm{N}}=\Delta \varepsilon+T_{\mathrm{N}, \text { Measured }} \\
& \Delta T_{\mathrm{N}}=T_{\mathrm{L}, \text { Literature }}-T_{\mathrm{N}}
\end{aligned}
$$

where $\Delta T_{\mathrm{N}}$ is the undercooling degree. To calibrate the temperature of the DSC curves, the eutectic temperature is taken as a reference temperature. According to the $T_{\mathrm{N}}$ and $T_{\mathrm{E}}$ values summarized in Table 1, the nucleation undercooling degree is also calculated and summarized in Table 1 . In the Al-7Si-0.1La alloy, the measured eutectic temperature is $598.53{ }^{\circ} \mathrm{C}$ and the theoretical eutectic value is $577^{\circ} \mathrm{C}$, so the $\Delta \varepsilon=-21.53{ }^{\circ} \mathrm{C}$. The nucleation temperature measured on the DSC curve is $623.69{ }^{\circ} \mathrm{C}$ and the theoretical liquidus value is $639.63{ }^{\circ} \mathrm{C}$. Finally, $\Delta T_{\mathrm{N}}$ is $37.47^{\circ} \mathrm{C}$. Similarly, $\Delta T_{\mathrm{N}}$ for Al-7Si alloy is $15.63{ }^{\circ} \mathrm{C}$. A relatively higher nucleation undercooling degree is 
obtained in Al-7Si-0.1 La alloys due to the addition of $0.1 \mathrm{wt} . \%$ La. Higher undercooling degree accelerates the nucleation of grains and precipitates suggesting that the nucleation is increased and subsequent growth is restrained. (a)

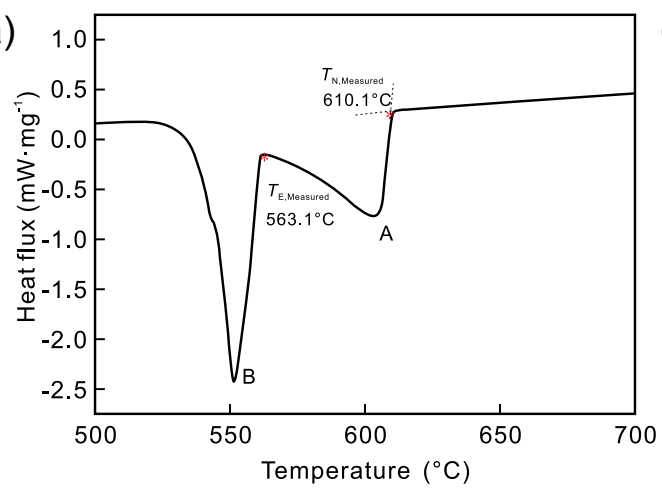

(b)

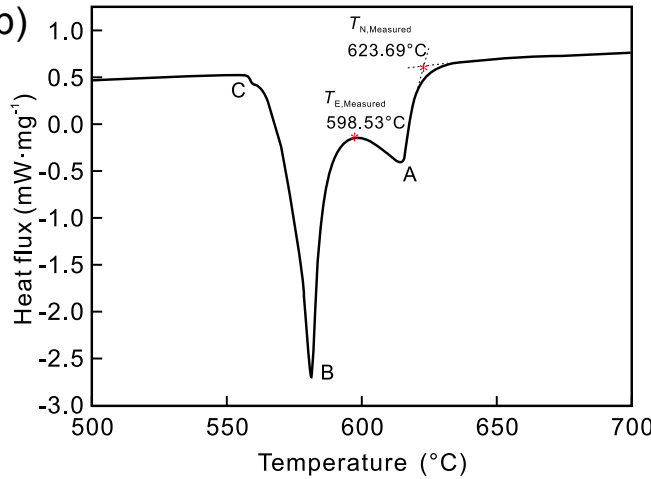

Fig. 1: DSC curves of Al-7Si (a) and Al-7Si-0.1 La (b) alloy

Table 1: Thermal analysis parameters in Al-7Si-xLa alloy

$\begin{array}{cccccc}\text { Samples } & T_{\mathrm{E}, \text { Measrued }}\left({ }^{\circ} \mathrm{C}\right) & T_{\mathrm{N}, \text { Measured }}\left({ }^{\circ} \mathrm{C}\right) & T_{\text {E,Literature }}\left({ }^{\circ} \mathrm{C}\right) & T_{\text {L,Literature }}\left({ }^{\circ} \mathrm{C}\right) & \Delta T_{\mathrm{N}}\left({ }^{\circ} \mathrm{C}\right) \\ \text { Al-7Si } & 563.1 & 610.1 & 577^{[21]} & 639.63^{[21]} & 15.63 \\ \text { Al-7Si-0.1La } & 598.53 & 623.69 & & & 37.47\end{array}$

\subsection{Microstructure}

Figure 2 shows representative eutectic structures of as-cast Al$7 \mathrm{Si}-x \mathrm{La}$ alloys observed by $\mathrm{OM}$ at low magnification. It can be seen from the metallographic structure that the alloy structure is composed of a primary $\alpha-\mathrm{Al}$ matrix, eutectic Si phase and a small amount of Fe-rich phase. Before and after the addition of La element, the alloy structures undergo significantly change, mainly reflect in the changes of the secondary dendrite arm spacing and the morphology and size of the Si particles. In the as-cast Al-7Si alloy without any modification [Fig. 2(a)], the eutectic Si particles present plate-like shape with large size $(10-15 \mu \mathrm{m})$ of low roundness and high aspect ratio. With the addition of $\mathrm{La}$, the eutectic Si particles present a fragmented shape, as shown in Figs. 2(b)-(d). In addition, a slight decrease in the Si particle size is achieved. However, due to the fibrous solidification characteristics of eutectic $\mathrm{Si}$, it is difficult to describe quantitatively. The Al-7Si alloy with different La addition contents at $\mathrm{T} 6$ heat-treated state is investigated and the microstructures are shown in Fig. 3.
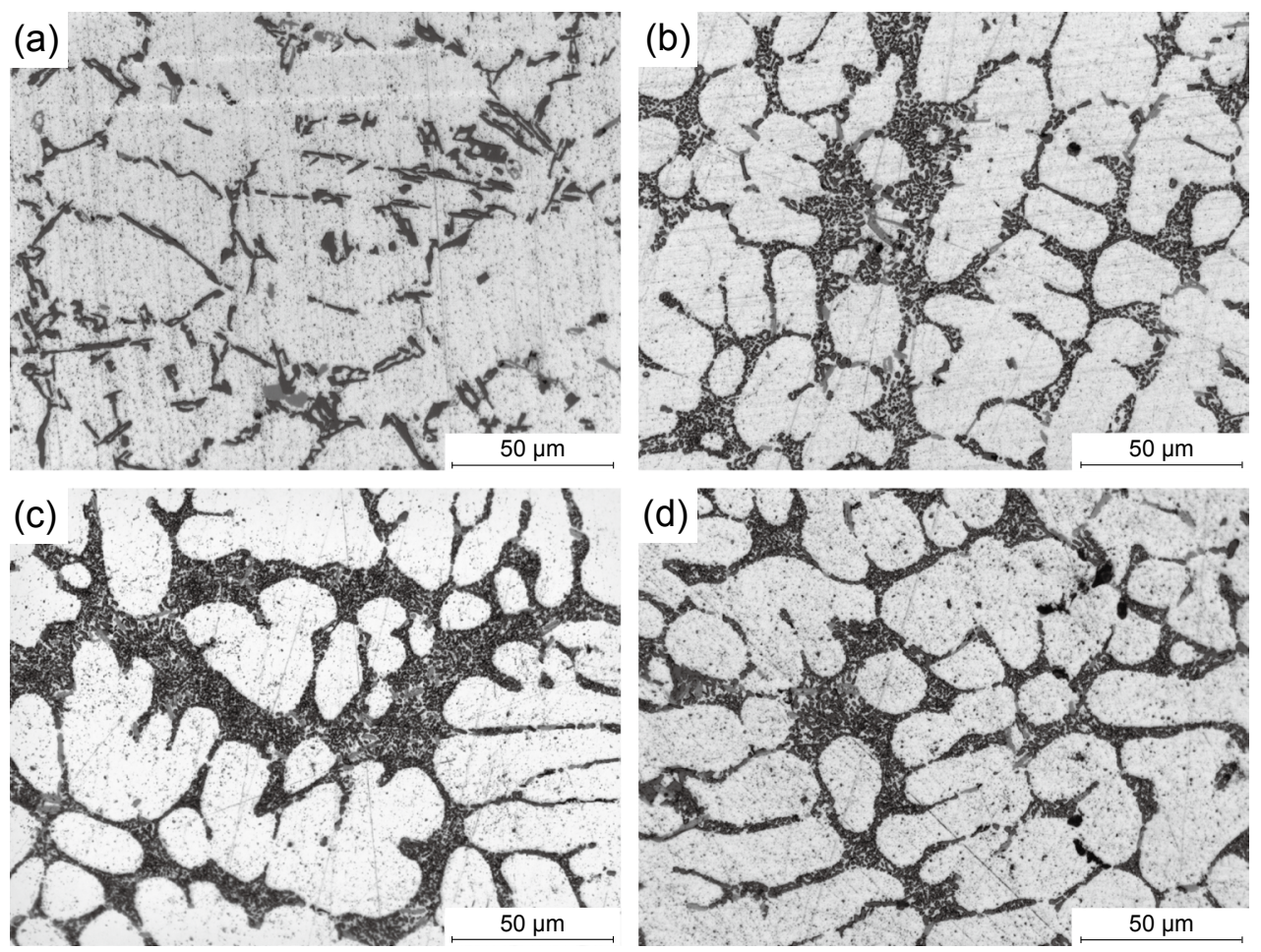

Fig. 2: Metallography of as-cast Al-7Si alloy with 0 (a), $0.1 w t . \%$ (b), $0.2 w t . \%$ (c), and $0.4 w t . \%$ (d) La 
It can be obtained from Fig. 3 that the T6 heat treatment process is beneficial to improve the morphology of eutectic Si phase from fibrous to globular shape. Because the solution heat treatment is carried out at a high temperature $\left(535^{\circ} \mathrm{C}\right)$, the solid solubility of $\mathrm{Si}$ in $\alpha$-Al matrix is high. In addition, the high temperature accelerates the atomic movement ability, which provides dynamic conditions for the transformation of Si phase. Due to the diffusion of atoms, the Si particles with lower distortion are formed. In order to reduce the interfacial energy as much as possible, Si particles tend to develop into spheres. Therefore, the spheroidization and granulation of eutectic Si particles occur after heat treatment process. In order to determine the effects of La element on the level of refinement observed in the above microstructures, the SDAS and size of eutectic Si particles (including the area of $\mathrm{Si}$ and aspect ratio of $\mathrm{Si}$ ) at $\mathrm{T} 6$ heat-treated state were measured using IPP 6.0 software and the results are shown in Table 2. It can be obtained from the values that compare with the microstructure of T6 heat-treated Al-7Si alloy, the SDAS and area of Si phase of Al-7Si-0.1La alloy at $\mathrm{T} 6$ heat-treated state are decreased by $7.9 \%$ and $7 \%$, respectively, which indicates that the La addition can refine both dendritic structure and eutectic Si particles. This is related to the high undercooling caused by the La element. However, when the La content is increased to $0.2 \mathrm{wt} . \%-0.4 \mathrm{wt} . \%$, the grain structure is coarsened. It also can be obtained from Fig. 3(d) that when the La addition content is increased to $0.4 \mathrm{wt} . \%$, a kind of La-rich phase with large size is formed in the alloy, which reduced the refining effect of La. In addition, due to the difference in size and content of La-rich phases between Al-7Si-0.2La and Al-7Si-0.4La, the Al-7Si-0.4La alloy shows better refining effect than Al-7Si-0.2La alloy.
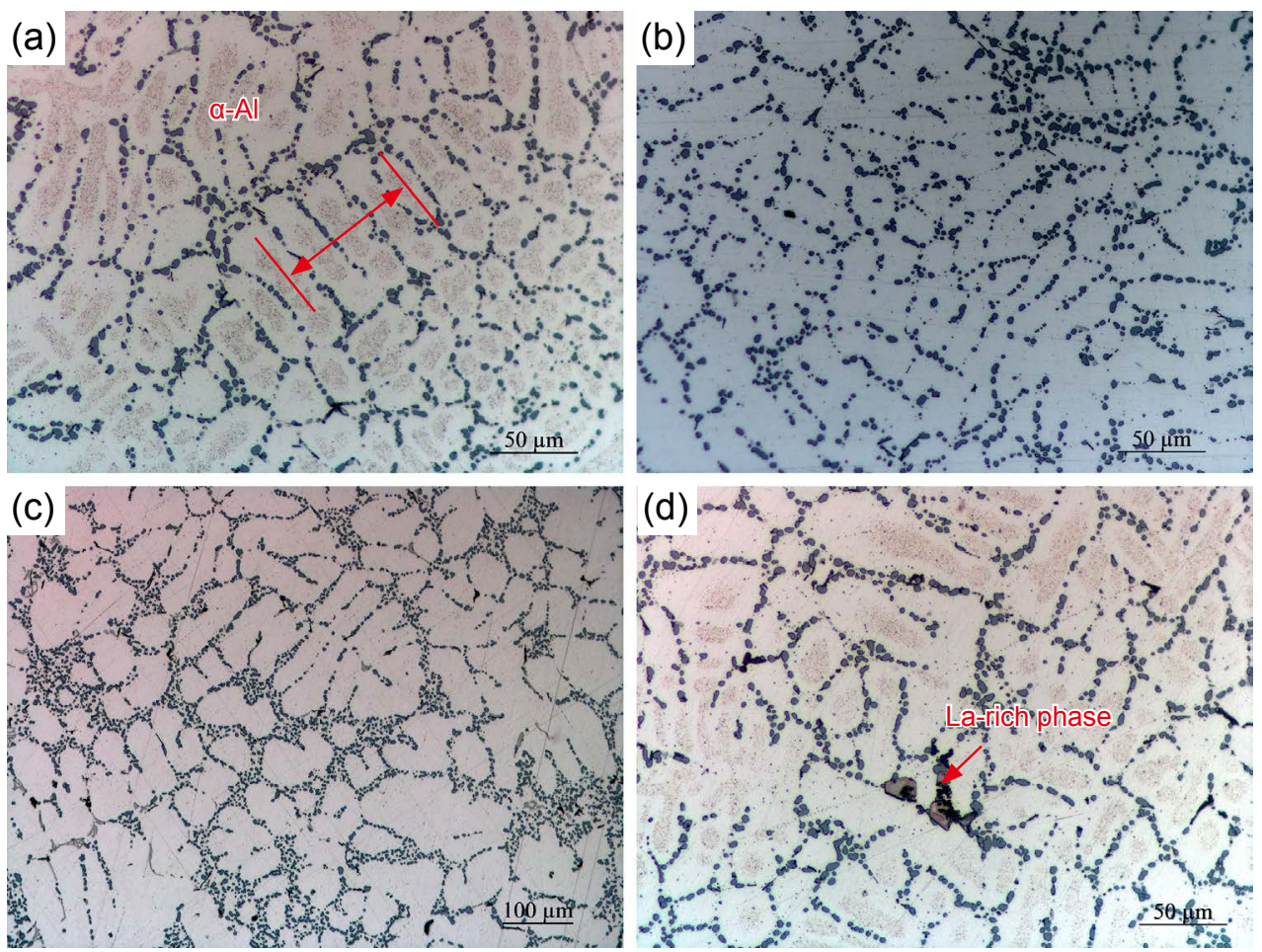

Fig. 3: Microstructures of T6 heat-treated Al-7Si-xLa alloys: (a) 0; (b) $0.1 w t . \%$ La; (c) $0.2 w t . \%$ La; (d) $0.4 w t . \%$ La

Table 2: SDAS and size of Si phase of Al-7Si-xLa alloy at T6 heat-treated state

\begin{tabular}{cccc}
$\begin{array}{c}\text { La content } \\
(w t . \%)\end{array}$ & $\begin{array}{c}\text { SDAS } \\
(\mu \mathrm{m})\end{array}$ & $\begin{array}{c}\text { Area of Si } \\
\left(\mu \mathrm{m}^{2}\right)\end{array}$ & Aspect ratio of Si \\
\hline 0 & 20.26 & $7.12 \pm 2.45$ & $1.46 \pm 0.17$ \\
0.1 & 18.66 & $6.62 \pm 1.27$ & $1.32 \pm 0.19$ \\
0.2 & 19.77 & $6.61 \pm 1.91$ & $1.38 \pm 0.18$ \\
0.4 & 19.05 & $6.46 \pm 1.87$ & $1.43 \pm 0.13$ \\
\hline
\end{tabular}

\subsection{Al-Si-xLa phase distribution}

The XRD spectra are used to identify the La-rich phases of T6 heat-treated alloys with different La contents and the results are presented in Fig. 4. The Al-7Si alloy is mainly composed of $\alpha$-Al matrix and eutectic Si particles. With the addition of La element into Al-7Si alloy, in addition to these main phases, the $\mathrm{Al}_{4} \mathrm{La}$ and $\mathrm{Al}_{2} \mathrm{Si}_{2} \mathrm{La}$ phases are found.

The comparison results of La element distribution between T6 heat-treated Al-7Si-0.1La and Al-7Si-0.4La alloys observed by EPMA are shown in Fig. 5. The La-rich particles are marked with white round circles in Fig. 5. In the alloy with $0.1 w t . \%$ La, a small number of La-rich phases are found and distribute uniformly in the alloy. These La-rich phases are $\mathrm{Al}_{4} \mathrm{La}$ phase without $\mathrm{Si}$ element. A large number of La-rich phases are observed to segregate in the vicinity of eutectic $\mathrm{Si}$ in the form of $\mathrm{Al}_{2} \mathrm{Si}_{2} \mathrm{La}$ phase. The average size of these Larich phases $\left(\mathrm{Al}_{4} \mathrm{La}\right.$ and $\left.\mathrm{Al}_{2} \mathrm{Si}_{2} \mathrm{La}\right)$ is about $0.5-1 \mu \mathrm{m}$. The La- 


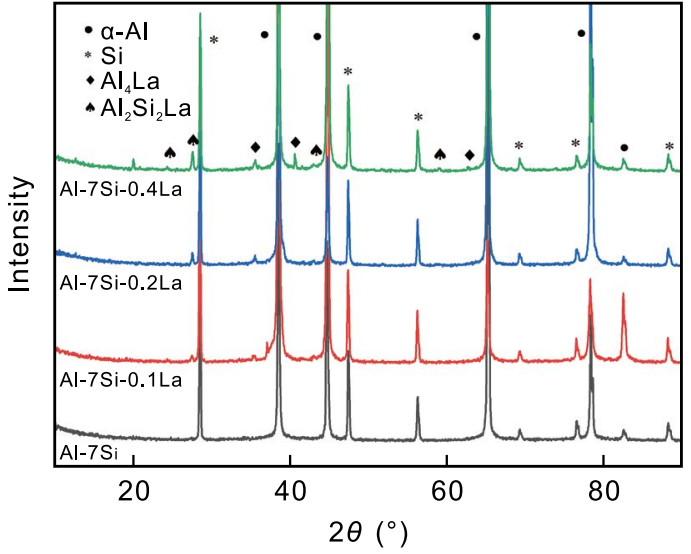

Fig. 4: XRD results of Al-7Si alloy with different La addition
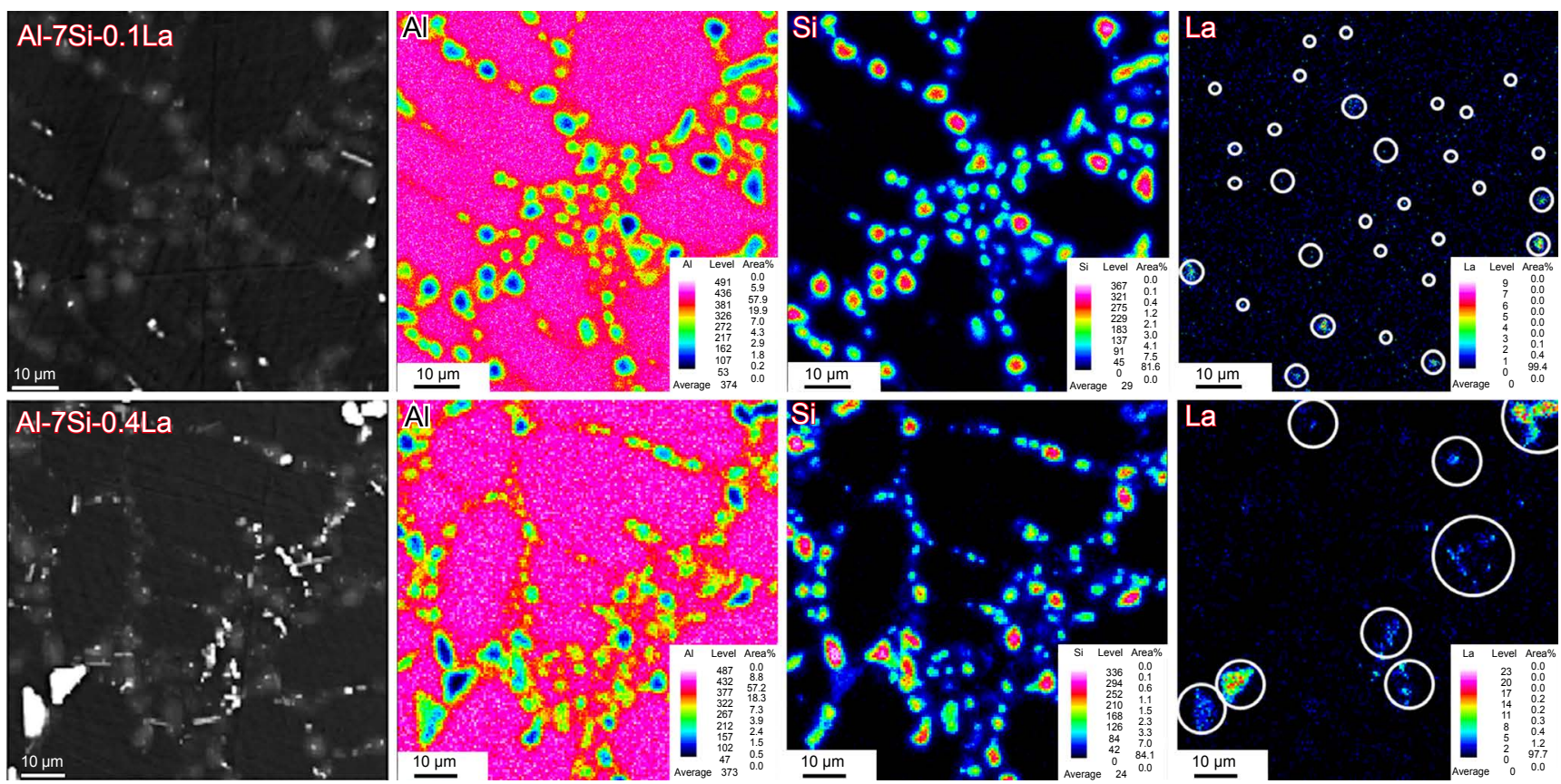

rich phases segregate strongly to the eutectic Si phase and no significant enrichment of La exists in the primary Al. This indicates that the pathway of the segregated La distribution is consistent with that of the eutectic Si particles. La element has a very limited solubility in $\mathrm{Al}$ and the maximum La solidsolubility in $\alpha$-Al measured is $0.26 \mathrm{wt} . \%$ at $625{ }^{\circ} \mathrm{C}$. During the solidification process, La atoms can be absorbed into the growth steps at the solid-liquid interface of $\mathrm{Si}$ particles and inhibit the growth of the eutectic Si particles, which can refine the eutectic Si particles. When the amount of La is increased to 0.4wt.\% (Fig. 5), the La segregates in the eutectic Si zone and La-rich phases are formed with the size larger than $7 \mu \mathrm{m}$. The refinement effect of these La-rich phases is weaker than those small La-rich phases in Al-7Si-0.1La alloy.

Fig. 5: EPMA mappings of Al-7Si alloy with $0.1 w t . \%{ }^{[22]}$ and $0.4 w t . \%$ La addition

\subsection{Tensile properties}

The tensile properties of hypoeutectic Al-7Si alloy with different $\mathrm{La}$ additions at $\mathrm{T} 6$ heat-treated conditions are presented in Fig. 6. The optimal ultimate tensile strength (UTS), yield strength (YS) and elongation reach $350.2 \mathrm{MPa}$, $275.5 \mathrm{MPa}$ and $12.75 \%$, respectively when the addition of $\mathrm{La}$ is $0.1 \mathrm{wt} . \%$. The ultimate tensile strength is enhanced by $5.2 \%$ (from $333 \mathrm{MPa}$ to $350.2 \mathrm{MPa}$ ) and the elongation is increased by $73 \%$ (from $7.37 \%$ to $12.75 \%$ ) compared with the Al-7Si alloy without La. However, the tensile properties are decreased when the addition content of La reaches $0.2 \mathrm{wt} . \%$.

The tensile properties of Al-7Si alloys are strongly dependent on grain size, SDAS, eutectic Si characteristics and so on. From the above observation, tensile properties of Al-7Si alloys are enhanced by the addition of La element, this is due to the reduction of SDAS value and the refinement of eutectic Si particles. Based on the analysis of previous studies ${ }^{[1-2,22]}$, the ductility is more sensitive to Si morphology. So modification brings about a significant increase in the ductility of Al-7Si alloy when the La content is $0.1 \mathrm{wt} . \%$ and the eutectic Si particles present granular morphology. However, when the amount of $\mathrm{La}$ is increased to $0.2 \mathrm{wt} . \%$, the formation of large brittle Larich phases cleaves the aluminum matrix and deteriorates

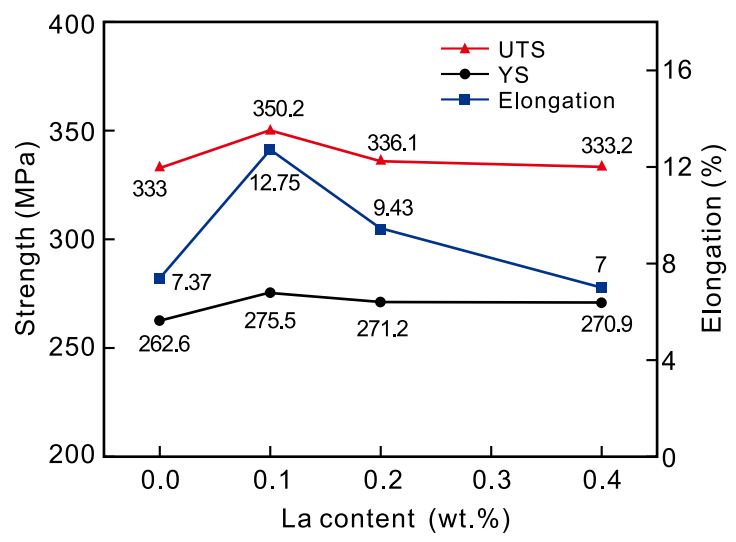

Fig. 6: Tensile properties of Al-7Si-xLa alloy at T6 heat-treated state 
the tensile properties of these alloys. Compared with the Al7Si-0.1La alloy, the tensile strength drops slightly and the elongation decreases dramatically in the Al-7Si-0.2/0.4La alloy.

\subsection{Fractography}

Figure 7 presents the SEM fractography of T6 heat-treated tensile specimens of Al-7Si alloy with different La contents. To elucidate the fracture mechanism, the EDS analysis is used to analyze the composition of phases (Point A, B and C in Fig. 7). The EDS analysis results are presented in Table 3.

As can be seen, the fracture surface of the T6 heat-treated Al-7Si alloy without La addition shows a mixture of quasicleavage and dimple morphology, extensive irregular cleavage planes and some tearing ridges. Therefore, the fracture mode is mixed ductile-brittle fracture. There are broken Si particles in the fracture surface of T6 heat-treated Al-7Si alloy, as shown in Fig. 7(e). Based on the composition in Table 3 (the weight percentage of $\mathrm{Si}$ is $77.07 \%$ at Point A), it is confirmed that the quasi-cleavage fracture surface is dominated by the Si phase. These coarse Si particles cause stress concentration during deformation and become the source of cracks, leading to lower elongation. It is noted in Fig. 7(b) that the Al-7Si alloy with the addition of $0.1 \mathrm{wt} . \%$ La displays a large number of deep and small dimples which suggest the fracture mode is ductile fracture. The size of the dimples on the fracture surface is about 5-10 $\mu \mathrm{m}$. The La-rich particles with small size are distributed between the dimples as shown in Fig. 7(f), which plays a role in
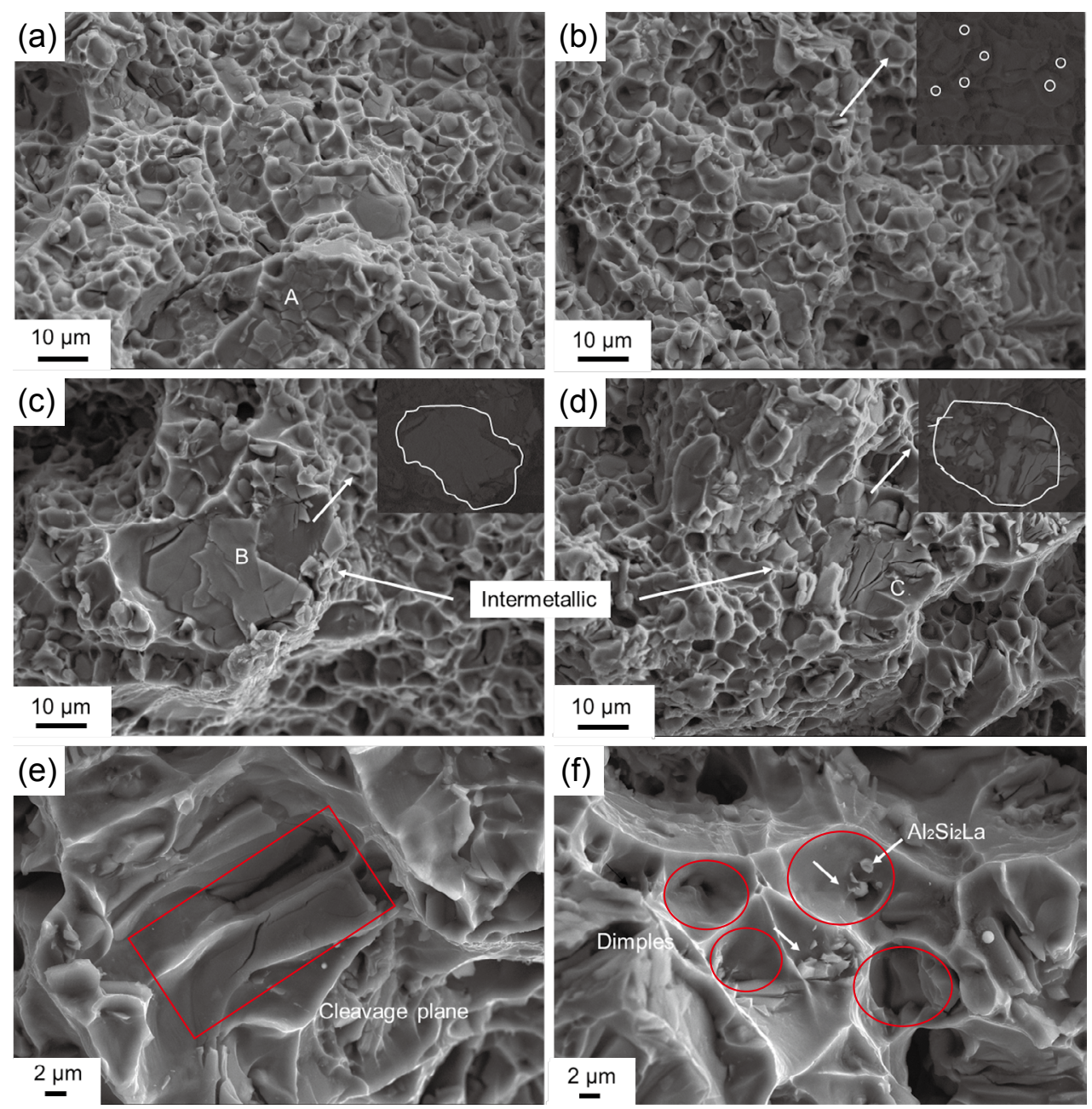

Fig. 7: Fracture surfaces of Al-7Si alloy with different contents of La after T6 process: (a) 0; (b) 0.1wt.\%; (c) $0.2 \mathrm{wt} . \%$; (d) $0.4 \mathrm{wt} . \%$; (e) magnified image of (a); (f) magnified image of (b)

Table 3: EDS analysis results of different fracture surfaces

\begin{tabular}{cccc|} 
& \multicolumn{3}{c|}{ Element content (wt.\%) } \\
\hline Position & Al & Si & La \\
\hline A & 22.93 & 77.07 & - \\
B & 59.99 & 15.58 & 24.43 \\
C & 23.47 & 24.80 & 51.73 \\
\hline
\end{tabular}

precipitation strengthening effect and thus improves the tensile properties. With the La addition, it can be seen that the addition of $0.1 \mathrm{wt} . \% \mathrm{La}$ decreases the size and increases the number of dimples slightly. This is consistent with the change of the size of SDAS and eutectic Si particles. With La content further increasing, there are massive coarse $\mathrm{Al}_{2} \mathrm{Si}_{2} \mathrm{La}$ phases in the fracture surface of alloy with $0.2 \mathrm{wt} . \%$ and 0.4wt.\% La in Figs. 7(c) and (d) (marked by white circle). These brittle phases act as stress concentrated points during 
tensile process, and thus brittle fracture occurs. Thus, the fracture mode of the alloy changes to the mixed ductilebrittle fracture mode. The strength and elongation are decreased correspondingly.

\section{Conclusions}

In the present study, the microstructure and fracture behavior of the Al-7Si alloys with different rare earth La addition contents were investigated and analyzed in detail. The main conclusions can be summarized as follows:

(1) When the rare earth La element is added into the Al7Si alloy, the La-rich phases precipitate in the form of $\mathrm{Al}_{4} \mathrm{La}$ and $\mathrm{Al}_{2} \mathrm{Si}_{2} \mathrm{La}$ phases in the eutectic zone. A relatively higher nucleation undercooling degree of $37.47^{\circ} \mathrm{C}$ is observed. Higher undercooling degree suggests that nucleation is accelerated and the growth of eutectic Si is restrained.

(2) Rare earth La can effectively refine the microstructure, such as SDAS and eutectic Si particles. The SDAS and area of Si particles in T6 heat-treated Al-7Si-0.1La alloy are decreased by $7.9 \%$ and $7 \%$, respectively compared with T6 heat-treated Al-7Si alloy. The optimal tensile properties are 350.2 MPa, 275.5 MPa and $12.75 \%$ for UTS, YS and elongation, respectively.

(3) The fracture behavior of Al-7Si alloy at T6 heat-treated state is ductile-brittle mixed fracture. With the refinement and homogenization of microstructure caused by the addition of $0.1 \mathrm{wt} . \% \mathrm{La}$, the fracture mode gradually transforms to ductile failure mode. The fracture mode evolves into ductile-brittle mixed fracture again in $\mathrm{Al}-7 \mathrm{Si}-0.2 / 0.4 \mathrm{La}$ due to the existence of large La-rich phase.

\section{Acknowledgements}

This work was supported by the Fundamental Research Funds for the Central Universities (Grant number FRFTP-19-083A1), the Guangxi Special Funding Programme for Innovation-Driven Development (Grant number GKAA17202008).

\section{References}

[1] Wu $X Y$, Yun $Y$, Zhang $H R$, et al. Effect of holding pressure on microstructure and fracture behavior of low pressure die cast A356-T6 alloy. Material Research Express, 2017, 4: 1-8.

[2] Wu XY, Zhang H R, Chen H L, et al. Evolution of microstructure and mechanical properties of A356 aluminium alloy processed by hot spinning process. China Foundry, 2017, 14(2): 138-144.

[3] Birol Y. Impact of grain size on mechanical properties of AlSi7Mg0.3 alloy. Materials Science and Engineering: A, 2013, 559: 394-400.

[4] Nogita K, Ysuda H, Yoshiya M, et al. The role of trace element segregation in the eutectic modification of hypoeutectic Al-Si alloys. Journal of Alloys and Compounds, 2010, 489: 415-420.

[5] Wu X Y, Zhang H R, Ma Z, et al. Interactions between Fe-rich intermetallics and Mg-Si phase in Al-7Si-xMg alloys. Journal of Alloys and Compounds, 2019, 786: 205-214.
[6] Samuel A M, Doty H W, Valtierra S, et al. Effect of grain refining and Sr-modification interactions on the impact toughness of AlSi-Mg cast alloys. Materials \& Design, 2014, 56: 264-273.

[7] Zhang L Y, Jiang $Y H$, Ma Z, et al. Effect of cooling rate on solidified microstructure and mechanical properties of aluminum-A356 alloy. Journal of Materials Processing Technology, 2008, 207(1-3): 107-111.

[8] Hosseini V A, Shabestari S G, Gholizadeh R. Study on the effect of cooling rate on the solidification parameters, microstructure, and mechanical properties of LM13 alloy using cooling curve thermal analysis technique. Materials and Design, 2013, 50: 7-14.

[9] Li D F, Cui C X, Wang X, et al. Microstructure evolution and enhanced mechanical properties of eutectic Al-Si die cast alloy by combined alloying $\mathrm{Mg}$ and La. Materials \& Design, 2016, 90: 820-828.

[10] Wan B B, Chen W P, Liu L S, et al. Effect of trace yttrium addition on the microstructure and tensile properties of recycled Al-7Si-0.3Mg-1.0Fe casting alloys. Materials Science and Engineering: A, 2016, 666: 165-175.

[11] Li J H, Wang X D, Ludwig T H, et al. Modification of eutectic Si in Al-Si alloys with Eu addition. Acta Materialia, 2015, 84: 153163.

[12] Tsai Y C, Chou C Y, Lee S L, et al. Effect of trace La addition on the microstructures and mechanical properties of A356 (Al-7Si-0.35Mg) aluminum alloys. Journal of Alloys and Compounds, 2009, 487(1-2): 157-162.

[13] Qiu C R, Miao S N, Xia X R, et al. Synergistic effect of Sr and La on the microstructure and mechanical properties of $A 356.2$ alloy. Materials \& Design, 2017, 114: 563-571.

[14] Karnesky R A, Dunand D C, Seidman D N. Evolution of nanoscale precipitates in $\mathrm{Al}$ microalloyed with $\mathrm{Sc}$ and Er. Acta Materialia, 2009, 57(14): 4022-4031.

[15] Dalen M E, Karnesky R A, Cabotaje J R, et al. Erbium and ytterbium solubilities and diffusivities in aluminum as determined by nanoscale characterization of precipitates. Acta Materialia, 2009, 57(14): 4081-4089.

[16] Li Q L, Li B Q, Li J B, et al. Effect of yttrium addition on the microstructures and mechanical properties of hypereutectic Al20Si alloy. Materials Science and Engineering: A, 2018, 722: 47-57.

[17] Liu S Q, Cui C X, Zhao L C, et al. Enhanced grain refinement of in situ CeB6/Al composite inoculant on pure aluminum by microstructure control. Journal of Alloys and Compounds, 2017, 701: 926-934.

[18] Gammer K, Ogris E, Uggowitzer P J, et al. SIMS investigations on the distribution of trace elements in modified aluminiumsilicon-magnesium alloys. Microchimica Acta, 2003, 141: 23-27.

[19] Wang T M, Zhao Y F, Chen Z N, et al. The bimodal effect of La on the microstructures and mechanical properties of in-situ A356$\mathrm{TiB}_{2}$ composites. Materials and Design, 2015, 85: 724-732.

[20] Du J F, Tu H, Peng H P, et al. Phase equilibria of the Al-Si-La system between 0 and 50 at. $\%$ La at 600 and $800{ }^{\circ} \mathrm{C}$. Journal of Alloys and Compounds, 2018, 765: 608-615.

[21] Jung $H$, Mangelinck-Noël N, Bergman C, et al. Determination of the average nucleation undercooling of primary Al-phase on refining particles from $\mathrm{Al}-5.0 \mathrm{wt} \% \mathrm{Ti}-1.0 \mathrm{wt} \% \mathrm{~B}$ in Al-based alloys using DSC. Journal of Alloys and Compounds, 2009, 477(1-2): 622-627.

[22] Wu X Y, Zhang $H$ R, Jiang $H T$, et al. Multi-refinement effect of rare earth lanthanum on $\alpha-\mathrm{Al}$ and eutectic Si phase in hypoeutectic Al-7Si alloy. Metal, 2020, 10(5): 621. 